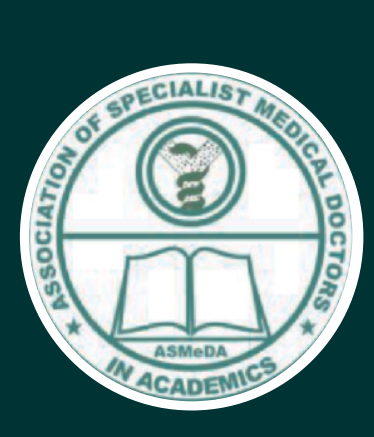

ISSN:Print: 2811-1672

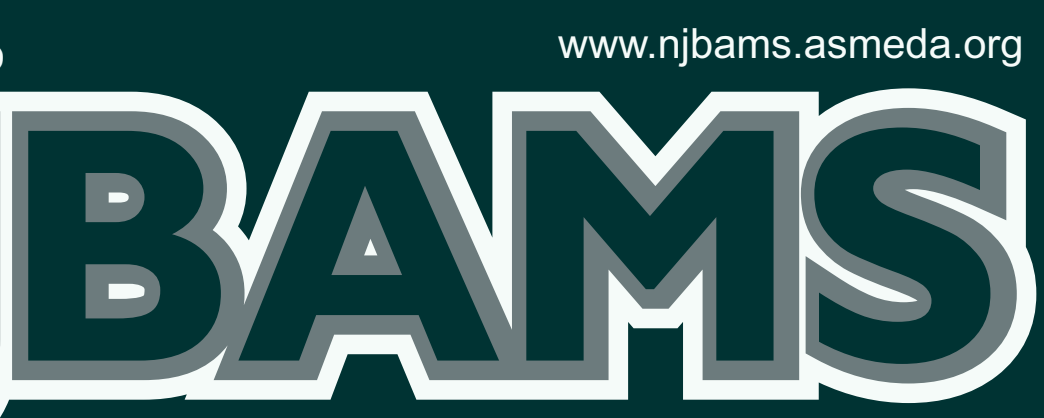

Nigerian Journal of Basic and Applied Medical Sciences

An official publication of the National

ASSOCIATION OF SPECIALIST MEDICAL DOCTORS IN

ACADEMICS (ASMeDA aka MEDSABAMS) 


\title{
Anti-Ulcerative Colitis Activity of the Aqueous Leaves Extract of Khaya Senegalensis in Acetic Acid-Induced Colitis Rat Model
}

\author{
Abdul Aziz S.L. ${ }^{1}$, Jimoh A.O. ${ }^{1}$, Yunusa A. ${ }^{1}$, Abdul mumini Y. ${ }^{2}$
}

${ }^{1}$ Department of Pharmacology, Faculty of Basic Clinical Sciences, College of Health Sciences, Usmanu Danfodiyo University Sokoto Nigeria. ${ }^{2}$ Department of Medicine, Faculty of Clinical Sciences, College of Health Sciences, Usmanu Danfodiyo University Sokoto Nigeria.

\begin{abstract}
Background: Ulcerative colitis is a chronic and relapsing inflammation of the gastrointestinal tract mainly colon. The disease is characterized by diarrhoea, blood in the stool, abdominal pain, and weight loss. Khaya senegalensis a plant commonly called dry zone Mahogany has been used as a remedy for several human gastrointestinal ailments.

Objectives: To investigate the effect of aqueous leaves extract of Khaya senegalensis in the acetic acid-induced ulcerative colitis rat model.

Study design: Preclinical randomised controlled trial.

Methods: extraction was done using water, initial phytochemical screening and oral LD50 were determined. Colitis was induced in rats using $4 \%$ acetic acid administered intra rectally. The rats were divided into five groups, group 1 received water, groups 2,3 , and 4 received graded doses of leaves extract while group 5 received prednisolone as the positive control. Symptomatic parameters like the daily stool consistency and appearance and histological parameters such as ulcer area, lesson severity score, ulcer index, weight/length ratio and percentage cure were measured.

Results; The leaves extract showed presence of alkaloids, tannins, flavonoids, saponins, steroids, volatile oil etc. The oral LD50 was greater than $5000 \mathrm{mg} / \mathrm{kg}$ and the efficacy of the $400 \mathrm{mg} / \mathrm{kg}$ extract administered group was not statistically significantly
\end{abstract}

different from the positive control group that received the standard drug prednisolone.

Conclusion: It can be concluded that the aqueous leaves extract of Khaya senegalensis possess significant anti-ulcerative colitis activity on acetic acid-induced ulcerative colitis rat models and appears to be safe.

Keywords: Ulcerative colitis, khaya senegalensis, acetic acid.

Corresponding Author: Shehu Lukman Abdul Aziz Address: Department of Pharmacology,

Faculty of Basic Clinical Sciences, College of Health Sciences,

Usmanu Danfodiyo University Sokoto Nigeria.

Email: shehulookthizman@gmail.com

Phone: 08060597659

\section{INTRODUCTION}

Traditional medicines of proven quality, safety, efficacy, contribute to the goal of ensuring that all people have access to care (1). The world Health organisation (WHO) encourages the integration of traditional and complementary medicine into policies of national health system by promoting its evidence-based use. It also encourages strategic research into traditional medicines by boosting clinical research projects on its safety and effectiveness (2).

Ulcerative colitis (UC) a constituent of inflammatory bowel disease (IBD) is a chronic and relapsing inflammation of insidious onset in the gastrointestinal tract mainly colon caused by variable pathophysiological mechanisms which includes genetics, environmental and immunological. The disease is characterized by clinical manifestations including diarrhoea, blood in the stool, abdominal pain, and weight loss (3). The complication of poorly managed ulcerative colitis includes toxic mega-colon, severe malnutrition, failure to thrive in children, severe dehydration, colonic fistula and predisposition to dysplasia and cancers.

Ulcerative colitis occurs throughout the world, its more common in urbanized and more developed parts of the world (first world countries) especially in the northern and western hemisphere presenting in the teens and early 20s (3). There is an increasing incidence and prevalence in Africa with considerable economic burden and effect on quality of life (4). There is a paucity of local data in Nigeria, although prevalence of $5 / 100,000$ was reported in South Africa (4). The current management of ulcerative colitis is aimed at inducing and maintaining remission medically using drugs like immuno-suppressants, amino-salicylates and steroids that are mostly toxic with low efficacy and not affordable especially in third world countries like Nigeria. As a result of the constraints in the orthodox management of ulcerative colitis an indigenous already familiar widely available, a safe and effective alternative is needed.

Cite this article as: Abdul Aziz S.L., Jimoh A.O., Yunusa A., Abdul mumini Y. AntiUlcerative Colitis Activity of the Aqueous Leaves Extract of Khaya Senegalensis in Acetic Acid-Induced Colitis Rat Model. Nig. J. Basic \& Applied Med. Sci. 2021; 1(1);19-22.
Khaya senegalensis is a plant in the family meliacae commonly called dry zone Mahogany (5) with documented anti-inflammatory (6), antibacterial (7) activities that has been used a remedy for several human gastrointestinal ailments like diarrhoea and dysentery (8). This study was designed to evaluate the anti-ulcerative colitis activity of aqueous leaves extract of Khaya senegalensis in acetic acidinduced colitis rats.

Despite the folkloric and scientific claims of the medicinal use of Khaya senegalensis in the management of several gastrointestinal diseases, like diarrhoea (8), bacterial (7) to the best of our knowledge no research has been conducted on possible antiulcerative colitis activity of Khaya senegalensis in acetic acid-induced ulcerative colitis rat models. The study aimed to determine the anti-ulcerative colitis activity of aqueous leaves extract of Khaya senegalensis in acetic acid-induced ulcerative colitis rat model.

\section{Methodology}

Study Location: The study was conducted at the Department of pharmacology and therapeutics, Faculty of Basic Clinical Science, College of Health Sciences, Usmanu Danfodiyo University, Sokoto Nigeria.

Experimental animals: Forty two (42) Young adult Wister albino rats at 6 to 8 weeks weighting between 150-200g with 50/50 male to female ratio were procured. They were kept in cages in a wellventilated room with optimum environmental conditions of temperature, relative humidity, dark/light cycle and were fed standard rat feed pellets and tap water. They were acclimatized for a period of two weeks before the experiment.

Plant Collection: The leaves of Khaya senegalensis used for this study were collected from a bush around Dundaye, Wammako Local Government Area of Sokoto State, Nigeria. The plant parts were authenticated at the Department of Pharmacognosy and Ethnopharmacy Faculty of Pharmaceutical Science, Usmanu Danfodiyo University, Sokoto with a voucher number of PCG/UDUS/MCL/0002.

Extract Preparation: The Collected leaves were cleaned and airdried at room temperature and ground to fine powder using mortar 
and pestle. The powdered materials were macerated in distilled water after which it was filtered. The filtrates were Concentrated and dried on water bath to give a yield of the aqueous leaves extract which was used for the study (9).

Phytochemical Screening: The air-dried extracted powder of the leaves of Khaya senegalensis was subjected to preliminary phytochemical screening: Tanins, phlobatannins and alkaloids by the method of Trease and Evans 1989 (10). Steroids, saponins, glycosides and flavonoids by Harborne 1973 (11) and terpenoids, by Sofowora 1993 (12)

Acute Toxicity: LD50 (oral) of the aqueous leaves extract was determined using the method of Lorke D (13). This method has 2 phases: phase 1 and phase 2 respectively:

Phase 1 acute toxicity study of the aqueous leaves extract of Khaya senegalensisis: Nine rats were divided into three groups of 3 animals each. Each group of animals were administered different doses $(10,100,1000 \mathrm{mg} / \mathrm{kg})$ of aqueous leaves extract of Khaya senegalensis. Mortalities within 24 hours were recorded for each group.

Phase 2 acute toxicity study of the aqueous leaves extract of Khaya senegalensisis: Three rats were divided into three groups of one rat each. The animals were administered high doses (1600, 2900 and $5000 \mathrm{mg} / \mathrm{kg}$ ) of aqueous leaves extract of Khaya senegalensis and then observed for mortality in twenty-four hours.

The LD50 was calculated by the formula:

$\mathrm{LD} 50=\sqrt{ }\left(\mathrm{D}_{0} \times \mathrm{D}_{100}\right)$.

$\mathrm{D}_{0}=$ Highest dose that gave no mortality.

$\mathrm{D}_{100}=$ Lowest dose that produced mortality.

Colitis induction: Colitis was induced in 30 fasted rats following the method of Jag tap (14). Two millilitres of 4\% acetic acid was injected intra rectally using a rectal catheter inserted at a depth of $6 \mathrm{~cm}$ for $15-30$ seconds followed by washing the colonic lumen with $2 \mathrm{mls}$ of distilled water.

Grouping and treatment of experimental animals: Twentyfour hours after the induction of colitis the rats were randomly assigned to 5 groups (I-V) of six animals each using computer generated numbers. The first group received 2 millilitres of distilled water (vehicle treated group) while group 2, 3 and 4 received graded doses of the aqueous leaves extract $(100 \mathrm{mg} / \mathrm{kg}$, $200 \mathrm{mg} / \mathrm{kg}$ and $400 \mathrm{mg} / \mathrm{kg}$ ) respectively for 5 days. Group 5 received the standard drug (prednisolone) $2 \mathrm{~m} / \mathrm{kg}$ for 5 days.

Daily Stool consistency and appearance during treatment: Daily Consistency and appearance of the stool produced by each rat during treatment was physically examined and scored using standard scoring pattern of masonubu et al 2002 (15).

Harvesting and staining of colonic specimen: A day post treatment the animals were sacrificed. Colonic segments of about $8 \mathrm{~cm}$ (at $2 \mathrm{~cm}$ proximal to the anus) were excised and cut opened along their mesenteric borders. The excised segment was washed with normal saline and viewed macroscopically (16). Some Portion of colonic specimens was stained with haematoxylin and eosin, fixed with paraffin, placed on glass slide, covered and viewed under a light microscope.

\section{Colonic mucosal parameters post treatment}

Determination of ulcer area: The ulcer area was determined by using a glass square graduated with cells measuring $1 \mathrm{~mm}^{2}$. The glass square was placed on the ulcerated area of the rat colon and the number of Glass Square accommodating the ulcerated part was counted.
Ulcer area $\left(\mathrm{mm}^{2}\right)=$ number of graduated glass square that covers the ulcerated colonic part $\times 1 \mathrm{~mm}^{2}$

Lesion severity score: Stained sections of the colons were evaluated under light microscopy. A Simplified Geboes histological score (17) was used to determine the lesion severity.

Ulcer index (UI): This was determined by the summation of ulcer area and lesion score.

Ulcer index $=$ ulcer area + lesson score.

Percentage cure (PC) for ulcerative colitis: This was calculated by:

PC = vehicle UI - treated groups U I / vehicle UI $\times 100 \%$

Data and statistical analysis: All the results were expressed as mean \pm Standard error of mean. Data analysis was performed using Graph Pad Prism 6.0 software (Graph Pad, San Diego, USA). Statistical comparison was made between treated groups and negative control groups using a one-way ANOVA and post hoc test. Value of $\mathrm{p}<0.05$ was considered to be statistically significant.

\section{Results}

Preliminary Phytochemical Screening: Phytochemical screening of aqueous leaves extract of Khaya senegalensis showed the presence of Alkaloids, tannins, flavonoids, Quinonic compounds, saponnins, steroids, Reducing sugars and volatile oils.

Table 1. Result of Preliminary Phytochemical Screening of aqueous leaves extract of Khaya senegalensis

\begin{tabular}{ll}
\hline Phytochemicals & Inference \\
\hline Alkaloids & Positive \\
Tannins & Positive \\
Flavonoids & Positive \\
Saponnins & Positive \\
Volatile oil & Positive \\
Steroids & Positive \\
Quinonic compounds & Positive \\
Glycosides & Negative \\
Reducing sugars & Positive \\
\hline
\end{tabular}

Acute Toxicity Study: No mortality was recorded in the two phases of acute toxicity studies of the aqueous leaves extract of Khaya senegalensis. The $\mathrm{LD}_{50}$ was therefore greater than $5000 \mathrm{mg} / \mathrm{kg}$ body weight of the extracts.

Table 2a. phase 1

\begin{tabular}{lll}
\hline Group 1 & Group 2 & Group 3 \\
$10 \mathrm{mg} / \mathrm{kg}$ & $100 \mathrm{mg} / \mathrm{kg}$ & $1000 \mathrm{mg} / \mathrm{kg}$ \\
\hline $0 / 3$ & & \\
\hline
\end{tabular}

Table 2b. phase 2

Group $1 \quad$ Group $2 \quad$ Group3

$1600 \mathrm{mg} / \mathrm{kg} \quad 2900 \mathrm{mg} / \mathrm{kg} \quad 5000 \mathrm{mg} / \mathrm{kg}$

$\begin{array}{lll}0 / 3 & 0 / 3 & 0 / 3\end{array}$


Effect of aqueous leaves extract of Khaya senegalensis on stool consistency and appearance in acetic acid-induced ulcerative colitis rat models: There was a significant reduction though not statistically significant, in the average daily stool consistency and appearance in all the extract treated groups when compared to the distilled water treated groups in the day 2, 3, 4 and 5 studies as shown in table 3 .

Table 3. Effect of aqueous leaves extract of Khaya senegalensis on daily stool consistency and appearance in acetic acid-induced ulcerative colitis rat models

\begin{tabular}{llllll}
\hline Days & $\begin{array}{l}\text { Group1 2mls } \\
\text { distilled water }\end{array}$ & $\begin{array}{l}\text { Group2 100mg/kg } \\
\text { extract }\end{array}$ & $\begin{array}{l}\text { Group3 200m/ } \\
\text { extract }\end{array}$ & $\begin{array}{l}\text { Group4 400mg/kg } \\
\text { extract }\end{array}$ & $\begin{array}{l}\text { Group5 2mg/kg } \\
\text { prednisolone }\end{array}$ \\
\hline 1 & $2.40 \pm 0.24$ & $2.20 \pm .20$ & $2.40 \pm 0.24$ & $2.60 \pm 0.24$ & $2.40 \pm 0.24$ \\
2 & $2.40 \pm .24$ & $2.20 \pm 0.20$ & $2.2 \pm 0.20$ & $2.20 \pm .20$ & $2.40 \pm 0.24$ \\
3 & $2.0 \pm 0.00$ & $1.40 \pm .24$ & $1.40 \pm 0.24$ & $1.20 \pm .20$ & $1.40 \pm 0.24$ \\
4 & $1.00 \pm 0.00$ & $0.60 \pm 0.24$ & $0.60 \pm 0.24$ & $0.60 \pm 0.24$ & $0.4 \pm 0.24$ \\
5 & $0.8 \pm 0.20$ & $0.60 \pm 0.24$ & $0.40 \pm 0.24$ & $0.40 \pm 0.24$ & $0.40 \pm 0.24$ \\
\hline \multicolumn{7}{l}{ Values were presented as mean SEM, $\mathrm{n}=5}$.
\end{tabular}

Values of the group with superscript * are statistically significant $(\mathrm{p}<0.05)$ compared to the negative control group.

Values of the group with superscript $* *$ are statistically significant $(\mathrm{p}<0.05)$ compared to the positive control group

Values of the group with superscript $* * *$ are statistically significant $(\mathrm{p}<0.05)$ compared to positive and negative control groups.

Effect of aqueous leaves extract of Khaya senegalensis on histologic and macroscopic parameters in acetic acidinduced ulcerative colitis in rats: There was a statistically significant reduction in the ulcer area, lesion severity score, ulcer index and weight to length ratio for the groups treated with increasing dose of the extract. Similarly, the percentage cure increases with increasing dose of the extract.

The ulcer area $(1.64 \pm 0.12)$ of the $400 \mathrm{mg} / \mathrm{kg}$ extract treated group was not statistically significantly different from the prednisolone treated group (1.52 \pm 0.86$)$. Again, the groups treated with $100 \mathrm{mg} / \mathrm{kg}$ and $200 \mathrm{mg} / \mathrm{kg}$ extract produce ulcer areas $(5.06 \pm 0.04$ and $3.38 \pm 0.18$ respectively) statistically significantly different from the negative and positive control groups $(5.6 \pm 0.11$ and $1.52 \pm 0.86$ respectively).

The lesion severity score of the $100 \mathrm{mg} / \mathrm{kg}$ extract treated group (4.2 \pm 0.37$)$ was statistically significantly different from the positive control group $(2.00 \pm 0.00)$, while the $200 \mathrm{mg} / \mathrm{kg}$ and $400 \mathrm{mg} / \mathrm{kg}$ extract treated groups were not statistically significantly different from the prednisolone treated group $(2.00 \pm 0.00)$.

The ulcer index of the $400 \mathrm{mg} / \mathrm{kg}$ extract treated group (3.64 \pm 0.12 ) was statistically significantly different from the distilled water treated group $10 \pm 0.27$ but not different from the positive control group that receives prednisolone. Again, the groups treated with $200 \mathrm{mg} / \mathrm{kg}$ extract produces an ulcer index of (5.4) statistically significantly different from the prednisolone (3.52 0.86) and distilled water $(10 \pm 0.27)$ treated groups. However, the lowest dose $(100 \mathrm{mg} / \mathrm{kg})$ of the extract treated group (9.260.40) was not statistically significantly different from the distilled water treated group (100.27).

Table 4. Effect of aqueous leaves extracts of Khaya senegalensis on histologic and macroscopic parameters in acetic acid induced ulcerative colitis in rats

\begin{tabular}{llllll}
\hline Groups & Ulcer area $\left(\mathrm{mm}^{2}\right)$ & $\begin{array}{l}\text { Lesson severity } \\
\text { score }\end{array}$ & Ulcer index & $\begin{array}{l}\text { Weight/ length } \\
\text { ratio }(\mathrm{w} / \mathrm{l})\end{array}$ & $\begin{array}{l}\text { Percentage } \\
\text { cure }(\%)\end{array}$ \\
\hline (Distilled water) & $5.6 \pm 0.11$ & $4.4 \pm 0.24$ & $10 \pm 0.27$ & $0.26 \pm 0.00$ & $0.00 \pm 0.00$ \\
$(100 \mathrm{mg} / \mathrm{kg}$ extract) & $5.06 \pm 0.04^{* * *}$ & $4.2 \pm 0.37^{* *}$ & $9.26 \pm 0.40^{* *}$ & $0.26 \pm 0.00^{* *}$ & $7.4 \pm 0.07^{+* *}$ \\
$(200 \mathrm{mg} / \mathrm{kg}$ extract & $3.38 \pm 0.18^{* * *}$ & $20 \pm 0.00^{*}$ & $5.40 \pm 0.18^{* *}$ & $0.16 \pm 0.0 *^{*}$ & $46 \pm 0.70^{\text {*** }}$ \\
$(400 \mathrm{mg} / \mathrm{kg}$ extract $)$ & $1.64 \pm 0.12^{*}$ & $20 \pm 0.00^{*}$ & $3.6 \pm \pm 0.12^{*}$ & $0.16 \pm 0.01^{*}$ & $63.6 \pm 0.28^{*}$ \\
$5(2 \mathrm{mg} / \mathrm{kg}$ & $1.52 \pm 0.86$ & $20 \pm 0.00$ & $3.52 \pm 0.86$ & $0.16 \pm 0.01$ & $64.8 \pm 0.30$
\end{tabular}

$\frac{\text { prednisolone) }}{\text { Values were presented as mean SEM, } n=5 \text {. }}$

Values of the group with superscript * are statistically significant $(\mathrm{p}<0.05)$ compared to the negative control group.

Values of the group with superscript $* *$ are statistically significant $(\mathrm{p}<0.05)$ compared to the positive control group.

Values of the group with superscript *** are statistically significant $(\mathrm{p}<0.05)$ compared to positive and negative control groups.

\section{Discussion}

The phytochemical analysis of aqueous leaves extract of Khaya senegalensis reveal that the extract is rich in alkaloids, tannins, flavonoids, steroids, quinonic compounds, triterpenoids, saponins, reducing sugar and volatile oil. The antidiarrheal activity of Khaya senegalensis may be attributed to the flavonoid and tannin constituents present in the extracts (18).

The result of acute toxicity study produced no mortality at a dose greater than $5000 \mathrm{mg} / \mathrm{kg}$ body weight. This means that the LD50 of the tested extract was higher than $5000 \mathrm{mg} / \mathrm{kg}$ which is above the cut off for toxicity profiling. This is similar to a result establishing the oral LD50 of aqueous stem bark extract of Khaya senegalensis to be $4200 \mathrm{mg} / \mathrm{kg}(19)$.

The acetic acid induced ulcerative colitis is a chemical colitis model with features similar to ulcerative colitis in humans including mucosal oedema, erythema, ulceration and subsequent white cell infiltration (20).

There was a significant improvement in the average daily stool consistency and appearance in all the groups receiving the leaves extracts in a dose dependent manner when compared with their negative control counterparts starting from day 2 of administration. This may be due to the antidiarrheal activity of some active compound in the plant extract. (8) (21).

The lesion severity scores of the $200 \mathrm{mg} / \mathrm{kg}$ and $400 \mathrm{mg} / \mathrm{kg}$ extract treated groups as well as the ulcer index of the $400 \mathrm{mg} / \mathrm{kg}$ extract treated groups were not significantly different from the positive control groups. This is an encouraging finding because lower doses of the extract may be equally efficacious as higher doses while minimizing the attending adverse effects. This is very important on chronic administration especially if it's earlier mentioned toxicity possibility is taken into consideration. Again, the ulcer area of the $400 \mathrm{mg} / \mathrm{kg}$ extracts treated group was not significantly different from the positive control prednisolone group further buttressing the efficacy of the extract. This could be explained by the antiinflammatory activity of the plant extracts (6), likely via an antiPLA2 activity. (22). This result is similar to a study on Calotropis procera and Hyplophyllum tuberculatum which found similar reduction in ulcer area, ulcer index, lesion severity score and percentage cure rates (23). Additionally, the percentage cure increases with increasing dosing of the extract, again in keeping with the significant reduction in the inflammatory parameters.

\section{Conclusion}

The aqueous leaves extract of Khaya senegalensis exhibit significant anti-ulcerative colitis activity in a dose dependent manner. The extracts also appear to be safe especially if administered acutely and at low dose.

\section{Recommendations}

Care should be taken when consuming high doses of the extract for a prolonged period due to the aforementioned toxicity possibilities and further research is needed to isolate the main active agent and determine the mechanism of action of the active agents.

\section{Acknowledgments}

The authors would like to thank the Usmanu Danfodiyo university sokoto and the university teaching hospital.

\section{Authors' contributions}

All the authors contributed to data collection and preparation of the manuscript. All authors read the final version and confirmed for the publication. 


\section{Conflict of interests}

The authors declare no conflict of interest regarding the publication of this paper.

\section{Ethical considerations}

Ethical issues have been observed by the authors. All the procedures were approved by the Ethical Committee of Usmanu Danfodiyo University, Sokoto, faculty of basic medical sciences, Department of pharmacology.

\section{References}

1. Margaret Chan World Health Organization congress on Traditional Medicine 7, 2008.

2. World Health organization (WHO), 2015. WHO Traditional medicine strategy $2014-2023$

3. Kumar, V., Abbas A.K., Aster, J.C. 2015. Robbins and Cotran's Pathologic Basis of Disease. 9th Edition. Elsevier-Saunders E-book, Chapter 17 - The Gastrointestinal Tract.

4. The global, regional, and national burden of inflammatory bowel disease in 195 countries and territories, 1990-2017: a systematic analysis of global burden of disease study 2017. Lancet Gastroenterol Hepatol, 2020, 5,17-30.

5. Danquah JA, M Appiah and A Pappinen. The effect of African mahogany species on soil chemical properties in degraded dry semi-deciduous forest ecosystems in Ghana. 2012. Int J Agric Biol, 14: 321-328.

6. Bum EN, GS Taiwe, FCO Moto, GT Ngoupaye, RRN Vougat, VD Sakoue, C Gwa, ER Ayissi, C Dong, A Rakotonirina and SV Rakotonirina, 2010. Antiepileptic Medicinal Plants Used in Traditional Medicine to Treat Epilepsy. In Clinical and Genetic Aspects of Epilepsy: 175-195.

7. Kubmarawa, D., M.E. Khan., A.M. Punah and M. Hassan. 2008. Phyto chemical screening and anti-microbial efficacy of extract from Khaya senegalensis against human pathogenic bacteria. African journal of Biotech, 7, 4563-4566.

8. Offiah, N.V., S, Makama., I.L. Elisha., M.S. Makoshi., J.G Gotep., C.J. Dawurung., O.O. Oladipo., A.S. Lohlum and D. Shamaki. 2011. Ethnobotanical survey of medicinal plants used in the treatment of animal diarrhea in Plateau State, Nigeria. BMC Vet Res, 7, 36

9. Akuodor GC, Essien AD, David-Oku E, Chilaka KC, Akpan JL, Ezeokpo B, Ezeonwumelu JOC. Gastroprotective effect of the aqueous leaf extract of Guiera senegalensis in albino rats.2013. Asian Pacific journal of tropical medicine 6 (10), 771-775.

10. Trease, G.E. and Evans, W.C. (1989): Pharmacognosy. 13th (ed). ELBS/Bailliere Tindall, London. Pp. 345-6, 535-6, 772-3.

11. Harborne J.B (1973). Phytochemical Methods. Chapman and Hall Ltd., London pp. 49-188.

12. Sofowora A (1993). Medicinal Plants and Traditional Medicine in Africa. Spectrum Books Ltd., Ibadan, Nigeria, pp. 191-289.

13. Lorke, D. 1983. A new approach to practical acute toxicity testing. Arch Toxicol, 53, 275-287.

14. Jagtap, A.E., Shirke, S.S., Phadke, A.S. 2004. Effect of Polyherbal formulation on experimental models of inflammatory bowel disease. J Ethnopharmacol, 90(2), 195-204.

15. Masonobu, F., Osamu, K., Yoshio, A., Akira, A., Kehchi, M., Kohsuke, T. Atsuchi, T., Masamichi, F., Yoshiaki, M., Tadao, B. 2002. Prebiotic treatment of experimental colitis with germinated barley food stuff: A comparison with probiotic or antibiotic treatment. Int J Molesco Med, 9, 65-70.

16. Amani, S. Awaad, Reham M. El-Meligy, Gamal, A., Soliman. 2013. Natura products in treatment of ulcerative colitis and peptic ulcer. Journal of Saudi Chemical Society,17, 101-124.

17. Geboes K., Riddell R., Öst A., Jensfelt B., Persson T., Löfberg R. 2000. A reproducible grading scale for histological assessment of inflammation in ulcerative colitis. Gut 2000, 47, 404-409.

18. Deepak, K., Ruali, S., Mihash, K. 2016. An overview of major classes of phytochemicals: their types and role in disease prevention. Hislopia journal, 91-2.

19. IU Muhammad, AJ Alhassan, AM Wudil, IK Jarumi Toxicological and protective effect of aqueous stem bark extract of Khaya senegalensis (ASBEKS) on liver of experimental rat. Current Journal of Applied Science and Technology, 600-605, 2015

20. Awaad, A.S., Alotiby, S.M., El-Meligy, R.M., Marzouk, M.S., Alqasoumi, S. I, Abd El Raheim, M. et al. 2016. Novel anti-ulcerogenic effects of total extract and isolated compounds from Cakile Arabica. In. J. Pharmacol. 12, 541-548.

21. Nwosu, C.U., S.W. Hassan., M.G. Abubakar and A.A. Ebbo. 2012. Anti-diarrhoeal and toxicological study of Khaya senegalensis. Journal of Pharmacology and Toxicology, 7,1-10.

22. Lompo, Marius., Guissou, I., Dubois, J., Dahaye, J-P., Oedrago, A., Traore, A., Some, N. Mechanism of anti-inflammatory activity of khaya senegalensis A Juss. (Meliaceae). 2007. Reference international journal of pharmacology, 3, 2, (137-142).

23. Amani S.A and Esraa A.A, 2018. Antiulcer and anti-ulcerative colitis activities of Haplophyllum tuberculatum(Forsskal). Int. J. Pharmacol., 14: 31-38. 